\title{
Systemic LPS administration induces brain inflammation but not dopaminergic neuronal death in the substantia nigra
}

\author{
Hey-Kyeong Jeong ${ }^{1,2}$, Ilo Jou ${ }^{1,2,3}$ and \\ Eun-hye Joe J,2,3,4,5 $^{-1,2}$ \\ ${ }^{1}$ Neuroscience Graduate Program \\ ${ }^{2}$ Department of Pharmacology \\ ${ }^{3}$ Chronic Inflammatory Disease Research Center \\ ${ }^{4}$ Brain Disease Research Center \\ Ajou University School of Medicine \\ Suwon 442-721, Korea \\ ${ }^{5}$ Corresponding author: Tel, 82-31-219-5062; \\ Fax, 82-31-219-5069; E-mail, ehjoe@ ajou.ac.kr \\ DOI 10.3858/emm.2010.42.12.085
}

Accepted 18 October 2010

Available Online 19 October 2010

Abbreviations: CD68, cluster of differentiation 68; DHEA, dehydroepiandrosterone; GFAP, glial fibrillary acidic protein; Iba-1, ionized calcium binding adaptor molecule 1; MPO, myeloperoxidase; NSAID, nonsteroidal anti-inflammatory drug; PD, Parkinson's disease; Q-PCR, quantitative polymerase chain reaction; SI, systemic inflammation; SN, substantia nigra; $\mathrm{TH}$, tyrosine hydroxylase

\begin{abstract}
It has been suggested that brain inflammation is important in aggravation of brain damage and/or that inflammation causes neurodegenerative diseases including Parkinson's disease (PD). Recently, systemic inflammation has also emerged as a risk factor for PD. In the present study, we evaluated how systemic inflammation induced by intravenous (iv) lipopolysaccharides (LPS) injection affected brain inflammation and neuronal damage in the rat. Interestingly, almost all brain inflammatory responses, including morphological activation of microglia, neutrophil infiltration, and mRNA/protein expression of inflammatory mediators, appeared within 4-8 $\mathrm{h}$, and subsided within 1-3 days, in the substantia nigra (SN), where dopaminergic neurons are located. More importantly, however, dopaminergic neuronal loss was not detectable for up to $8 \mathrm{~d}$ after iv LPS injection. Together, these results indicate that acute induction of systemic inflammation causes brain inflammation, but this is not sufficiently toxic to induce neuronal injury.
\end{abstract}

Keywords: brain inflammation; neuronal damage;

\author{
systemic inflammation
}

\section{Introduction}

Parkinson's disease (PD) is the second most common neurodegenerative disorder and is characterized by degeneration of dopaminergic neurons in the substantia nigra pars compacta (SNpc), resulting in movement disorder (Gelb et al., 1999). However, as most $(90-95 \%)$ cases of PD are sporadic in nature, it remains unclear how PD occurs and progresses. Mutations in genes such as those encoding $\alpha$-synuclein, parkin, PINK1, DJ-1, LRRK2, and Htra2 are found in familial PD patients (Klein et al., 2005; Klein and Schlossmacher, 2006; Thomas and Beal, 2007). However, animals carrying mutations in or knock-outs of these PD-related genes rarely show PD-like symptoms or dopaminergic neuronal loss (Rockenstein et al., 2002; Goldberg et al., 2003; Itier et al., 2003; Von Coelln et al., 2004; Chen et al., 2005b; Zhu et al., 2007). These findings indicate that abnormal functioning of PD-related genes is not enough to cause PD. Thus, certain microenvironmental factors such as brain inflammation have been suggested as important in causation and/or aggravation of neurodegenerative diseases includeing PD (Herrera et al., 2000; Gao et al., 2002). In PD brains, the expression levels of proinflammatory cytokines are higher than in control brains (Mogi et al., 1994; Blum-Degen et al., 1995; Muller et al., 1998; Knott et al., 2000; Nagatsu and Sawada, 2005; Whitton, 2007). Microglia (brain macrophages) are activated in post-mortem PD brains (McGeer et al., 1988; Croisier et al., 2005) and many experimental models of PD (Liberatore et al., 1999; Dehmer et al., 2000; Cicchetti et al., 2002; Wu et al., 2002; Sriram et al., 2006; Vijitruth et al., 2006). It has been suggested that nonsteroidal anti-inflammatory drug (NSAID) use reduces the incidence of PD (Chen et al., 2003; Esposito et al., 2007; Samii et al., 2009), although this contention remains controversial (Chen et al., 2005a; Etminan et al., 2008).

Brain damage induces brain inflammation. Microglia, known to be the principal inflammatory cells in the brain, continuously survey the environment of the normal brain and rapidly respond to damage, producing inflammatory mediators (Kreutzberg, 1996; Raivich et al., 1999; Min et al., 
2004; Davalos et al., 2005; Hanisch and Kettenmann, 2007). Systemic inflammation may also induce brain inflammation. Systemically administered LPS may act on endothelial cells in the brain, in turn affecting adjacent microglia (Cao et al., 1999; Inoue et al., 2002; Rummel et al., 2008; Saper, 2010). In addition, inflammatory cells of the bloodstream, activated by systemically administered LPS, may enter the brain and participate in inflammation (Bohatschek et al., 2001; Cunningham et al., 2005; Qin et al., 2007). However, it is not clear whether systemic inflammation induces a level of brain inflammation sufficiently intense to cause neuronal damage. Cultured microglia challenged with LPS and interferon- $\gamma$ produce neurotoxic inflammatory mediators including inducible nitric oxide synthase (iNOS) (Liu et al., 2000; Possel et al., 2000; Min et al., 2006), whereas microglia activated in vivo by brain injury and/or LPS injection synthesize very little iNOS and are not neurotoxic (Ji et al., 2007; Matsumoto et al., 2007). In the present study, we investigated how systemic inflammation affected brain inflammation, and whether such inflammation caused neuronal toxicity.

\section{Results}

\section{Behavior of microglia and astrocytes in response to systemic administration of LPS}

To investigate how systemic inflammation (SI) influenced the brain, we first examined the behavior of microglia and astrocytes after systemic administration of LPS. We focused on the SN region because inflammation in this area has been suggested as a risk factor for degeneration of dopaminergic neurons, resulting in PD. When 100 and $500 \mu \mathrm{g}$ amounts of LPS in $250 \mu \mathrm{l}$ PBS were intravenously (iv) injected into rats weighing 230-250 g, the TNF- $\alpha$ level in plasma increased sharply within $1 \mathrm{~h}$, but decreased rapidly to the basal level by $3 \mathrm{~h}$, as previously described (Liaudet et al., 2002; Chow et al., 2005; Qin et al., 2007). There was no significant difference in tumor necrosis factor-alpha (TNF- $\alpha$ ) levels after injection of 100 and $500 \mu \mathrm{g}$ LPS (Supplemental Data Figure S1), and we thus used 250 or $500 \mu \mathrm{g}$ LPS in various experiments. In PBS-treated control animals, ionized calcium binding adaptor molecule 1-immunopositive $\left(\mathrm{Iba}-1^{+}\right)$microglia showed a ramified morphology (Figure $1 \mathrm{~A}$ ). Microglial cell density in the substantia nigra reticulate $(\mathrm{SNr})$, where dopaminergic neuronal processes are located, was higher than that in the $\mathrm{SNpc}$, as previously reported (Ji et al., 2007). The processes of $\mathrm{Iba}^{+}{ }^{+}$ microglia became slightly shorter and thicker $8 \mathrm{~h}$ after iv LPS injection, and these features were more prominent in the SNpc than in the SNr. By 24 $\mathrm{h}$ post-injection, morphology had returned to normal (Figure 1A).

Astrocyte behavior was also examined in rat brains after induction of SI. Astrocyte density in the $\mathrm{SNpc}$ was much lower than in the SNr (Figure 1B). In contrast to what was noted when microglia were studied, there was no dramatic change in either morphology or astrocyte number in either region after iv LPS injection (Figure 1B). These results indicate that systemic LPS administration rapidly (within $8 \mathrm{~h}$ ) induces brain inflammation, particularly microglial responses.

\section{Neutrophils infiltrate the brain in response to systemic administration of LPS}

Neutrophils are recruited to LPS-injected, traumatic, and ischemic brains, and the inflammatory responses are neurotoxic ( $\mathrm{Ji}$ et al., 2007; Matsumoto et al., 2007). Thus, we examined the neutrophil infiltration pattern of the brain in response to
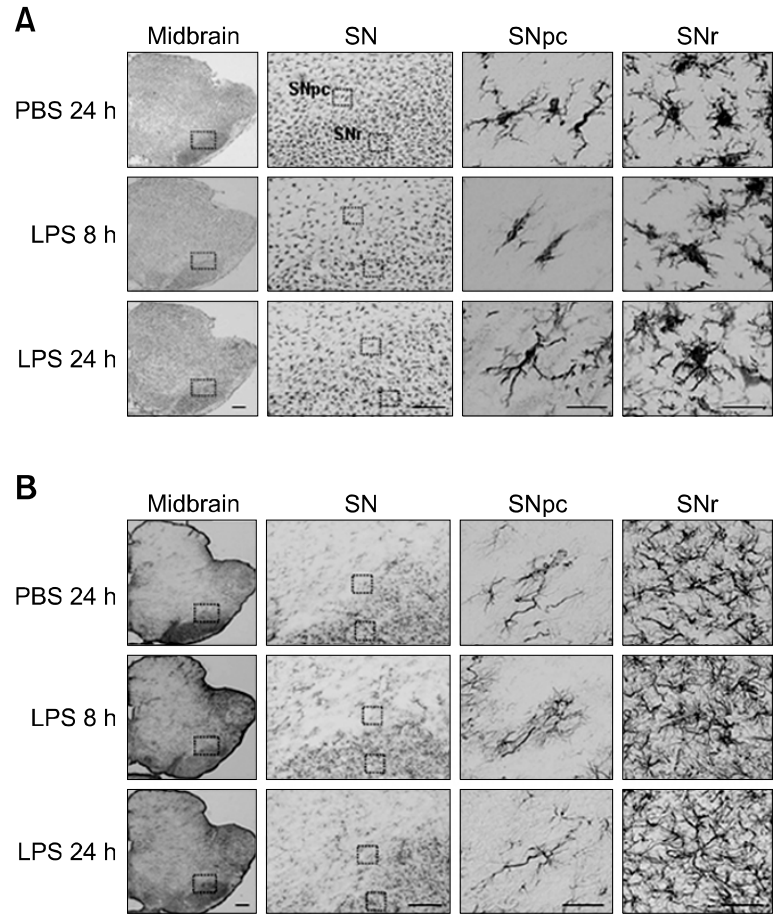

Figure 1. Behavior of microglia and astrocytes in response to iv LPS administration. Rats were injected iv with LPS $(250 \mu \mathrm{g})$ dissolved in 250 $\mu \mathrm{l}$ PBS, or with PBS alone. At the indicated times after injection, brains were removed and prepared for immunohistochemistry as described in Methods. Midbrain sections ( $30 \mu \mathrm{m}$ in thickness) were stained with anti-lba-1 (A) or anti-GFAP antibody (B), and expression of Iba-1 or GFAP was visualized using peroxidase-conjugated secondary antibodies. Scale bars: $200 \mu \mathrm{m}$ in the two left columns; $20 \mu \mathrm{m}$ in the two right columns. 
iv LPS injection. To this end, brain sections were stained for a marker of neutrophils, myeloperoxidase (MPO). In the SN, MPO ${ }^{+}$cells (arrows) were barely detectable within $4 \mathrm{~h}$ of LPS injection, increased in number at $8 \mathrm{~h}$, and decreased in level at 16-24 h (Figure 2A). However, fewer neutrophils infiltrated the brain after iv LPS injection compared with the numbers seen after direct intranigral infusion of LPS (Figure 2A). We also investigated whether the $\mathrm{SN}$ was more permeable to neutrophils than were other brain regions, and found that neutrophils appeared to infiltrate the $\mathrm{SN}$ and the cortex to similar extents (Figure $2 \mathrm{~B}$ ). These results indicate that the $\mathrm{SN}$ is not particularly prone to infiltration of neutrophils during systemic inflammation.

\section{Expression of proinflammatory mediators in response to systemic administration of LPS}

Next, in the $\mathrm{SN}$, we examined expression of mRNAs encoding proinflammatory mediators such as interleukin-1 beta (IL-1 $\beta$, TNF- $\alpha$, and interleukin-6 (IL-6), in response to systemic administration of LPS, using real-time quantitative polymerase chain reaction (Q-PCR). All tested mRNA levels increased within $4 \mathrm{~h}$ after iv LPS injection, peaked at $8 \mathrm{~h}$, and then to close to (or slightly greater than) basal levels (Figure 3A).

Upon immunohistochemical analysis, IL-1 $\beta$ expression was barely detectable $4 \mathrm{~h}$ after LPS administration, increased at 8-16 $\mathrm{h}$, decreased at $24 \mathrm{~h}$, and completely disappeared by $3 \mathrm{~d}$ (Figure $3 \mathrm{~B})$. We also investigated the expression of iNOS catalyzing nitric oxide production (Bogdan, 2001; Aktan, 2004), and cluster of differentiation 68 (CD68) representing phagocytic status (da Silva and Gordon, 1999; Nerlich et al., 2002; Rezaie et al., 2005). In contrast to what was seen when IL-1 $\beta$ expression was studied, only a limited number of cells expressed iNOS and CD68 (Figure 3B). Interestingly, IL-1 $\beta$ was detected in $\mathrm{Iba}-1^{+}$but not in $\mathrm{MPO}^{+}$cells, whereas iNOS and CD68 were detected in $\mathrm{MPO}^{+}$but not in ${\mathrm{Iba}-1^{+}}^{+}$cells (Figure $3 \mathrm{C})$. Together, these results indicate that systemic inflammation induced transient expression of proinflammatory mediators, and that microglia and neutrophils synthesized different subsets of such mediators.

\section{Effect of systemic administration of LPS on dopaminergic neuronal viability}

Although iv LPS injection induced brain inflammation, such inflammation was transient and relatively mild compared with that seen after direct injection of LPS into the brain (Ji et al., 2007). Thus, we examined whether systemic inflammation induced dopaminergic neuronal injury. In PBS-injected rats, dopaminergic neurons was unaffected (Figure 4A). In LPS-injected rats, dopaminergic neuronal loss was not detectable for up to $8 \mathrm{~d}$ after LPS administration (Figure 4A). Upon stereological counting, the numbers of dopaminergic neurons did not differ significantly after injection of PBS $(15,100 \pm 1,754$ cells, mean \pm SEM $)$ or LPS $(15,900 \pm 2,587$ cells, mean $\pm S E M)$ (Figure 4B, $P>0.05)$. Together, these results indicate that,

A

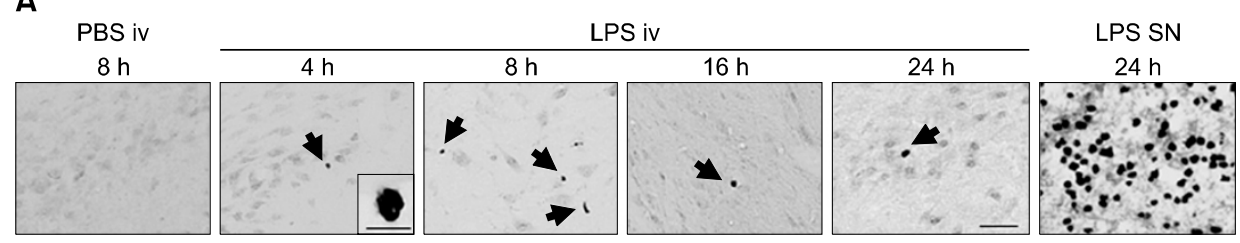

B
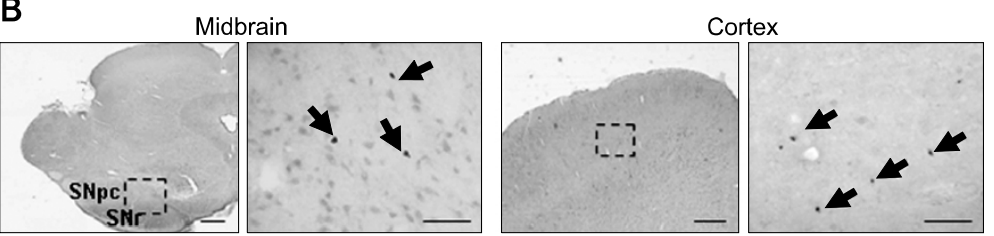

Figure 2. Neutrophils infiltrate the brain in response to iv LPS administration. (A) Sections were obtained from the midbrain at the indicated times after LPS injection (LPS iv), or $24 \mathrm{~h}$ after direct LPS injection into the SN (LPS $\mathrm{SNpc}$ ), and stained with an anti-MPO antibody. PBS-injected brain sections were used as positive controls. (B) Brain sections were obtained from the midbrain and the cortex $8 \mathrm{~h}$ after iv LPS injection, stained with an anti-MPO antibody, and MPOexpression was visualized using a peroxidase-conjugated secondary antibody. Scale bars: $200 \mu \mathrm{m}$ (left panels in B); $50 \mu \mathrm{m}$ (A and right panel of each region in B); and $10 \mu \mathrm{m}$ (inset in A). 

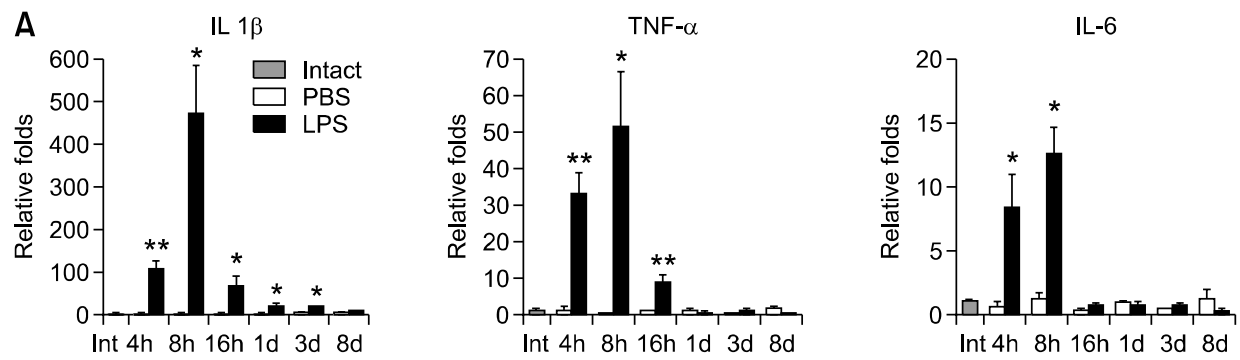

B
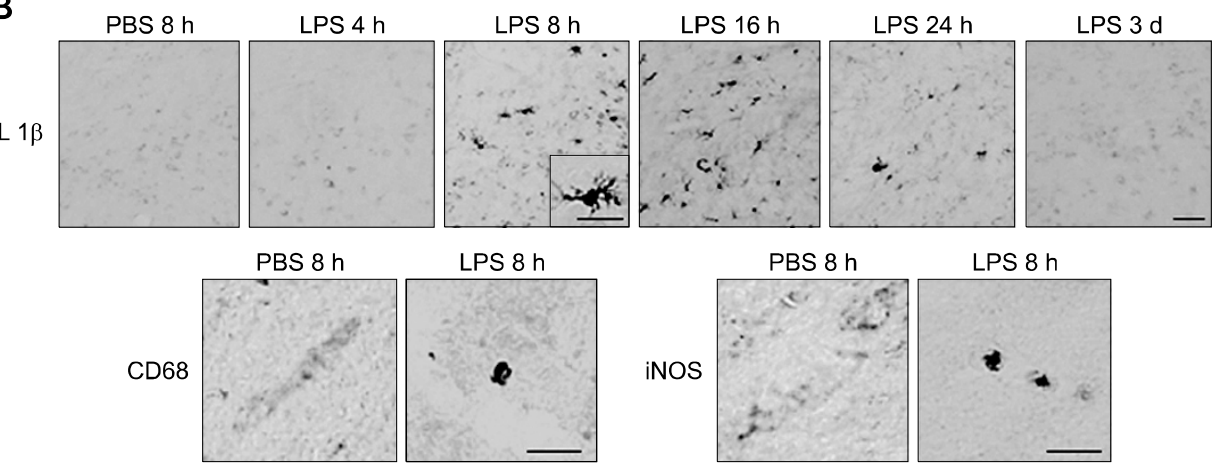

PBS $8 \mathrm{~h} \quad$ LPS $8 \mathrm{~h}$

C
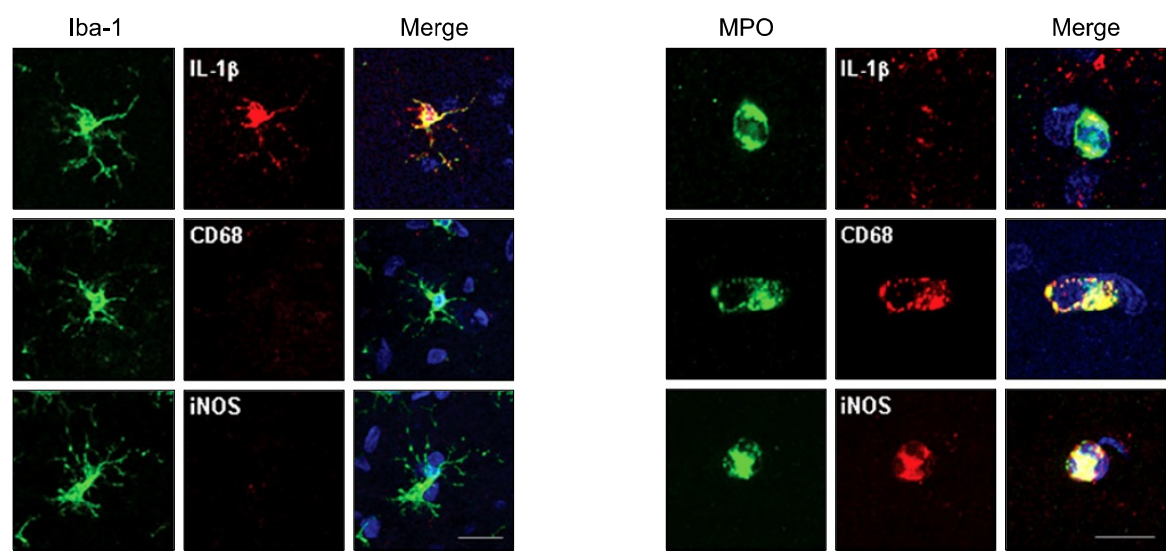

Figure 3. Expression of proinflammatory mediators in the brain in response to iv LPS injection. (A) mRNA was isolated from the midbrain regions of rats at the indicated times after iv LPS injection, and the levels of mRNAs encoding IL-1 $\beta$, TNF- $\alpha$, and IL- 6 were analyzed by Q-PCR. Values are means \pm SEMs of data from 3-5 animals. ${ }^{*} P<0.05$; ${ }^{* *} P<$ 0.01 , compared to intact brain. $(B, C)$ Sections were obtained from the midbrain at the indicated times after LPS or PBS injection, and stained with antibodies detecting IL-1 $\beta$, CD68, or iNOS; peroxidase-conjugated secondary antibodies (B) or double-labeled antibody combinations (C) were used to visualize binding. Midbrain sections of brains from animals injected iv with LPS were obtained at the indicated times and stained with the combinations of antibodies shown. Scale bars: $50 \mu \mathrm{m}$ (upper panels in B); $20 \mu \mathrm{m}$ (inset in the upper panel, and the lower panels in B); and $10 \mu \mathrm{m}$ (C).

although acute systemic inflammation indeed induces brain inflammation, the effect is mild and does not cause neuronal injury.

\section{Discussion}

It has been suggested that systemic inflammation may affect both the onset and progression of chronic brain diseases including PD and Alzheimer's disease, by induction of brain inflammation (Breitner, 1996; in 't Veld et al., 2002; Chen et al., 
A

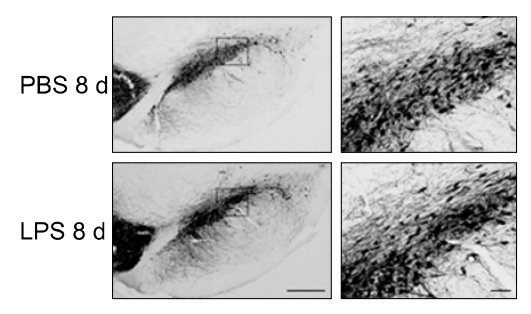

B

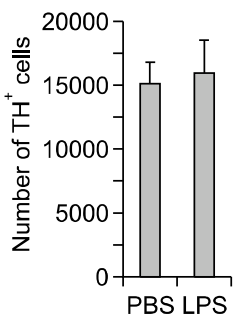

Figure 4. LPS administration iv does not influence dopaminergic neuronal viability. (A) Midbrain sections of animals receiving LPS or PBS iv were obtained at $8 \mathrm{~d}$, and stained with an anti-TH antibody. Scale bars: $200 \mu \mathrm{m}$ (left panels) and $50 \mu \mathrm{m}$ (right panels). (B) By stereology, the total numbers of $\mathrm{TH}^{+}$neurons were estimated in the SNpc of LPS- or PBS-injected rats, as described in Methods. Values are means \pm SEMs of data from three animals.

2003; Klegeris and McGeer, 2005; Esposito et al., 2007; Perry et al., 2007; Samii et al., 2009). The results of the present study show that iv LPS injection indeed induced brain inflammation. Microglia became morphologically activated; neutrophils infiltrated the brain; and inflammatory mediators, including IL-1 $\beta$, TNF- $\alpha$, IL-6, iNOS, and CD68, were synthesized (Figure 1-3). However, no neuronal death was evident (Figure 4). These results indicate that systemic inflammation indeed causes brain inflammation, but to only a mild extent and does not result in neuronal death.

The extent of neutrophil infiltration may significantly influence the level of neuronal death in an injured brain. Neutrophils are a major source of proinflammatory mediators including iNOS, Cyclooxygenase-2, Monocyte chemotactic protein-1, which play important roles in neuronal death within LPS-injected and/or ischemic brains ( $\mathrm{Ji}$ et al., 2007; Matsumoto et al., 2007). Previously, we found that direct injection of LPS recruited more neutrophils to the $\mathrm{SN}$ than to the cortex or hippocampus, which suggests that susceptibility to LPS neurotoxicity may differ among these regions (Figure 2B LPS SN; Ji et al., 2008). LPS iv injection recruited fewer neutrophils than did direct LPS injection (Figure 2B), and induced only transient expression of inflammatory mediators, lasting for up to 1-3 d (Figure 1-3). Previously, it was reported that a single intraperitoneal LPS injection increased TNF- $\alpha$ mRNA and protein expression levels in the brain for more than 10 months (Qin et al., 2007). Although we did not analyze the expression levels of inflammatory mediators at such late timepoints, it may be difficult to re-stimulate inflammatory responses after they subside, in the absence of a challenge, for several reasons. First, cerebrospinal fluid is renewed about
11 times daily in adult rats and maintains homeostasis of the brain environment (Johanson et al., 2008). Second, neutrophils of the brain, the major source of proinflammatory mediators, die 1-5 days after LPS intranigral injection, reflecting an early response to damage (Ji et al., 2007). Third, The suppressor of cytokine signaling family proteins and antioxidant enzymes that resolve inflammation processes are activated to prevent long-lasting inflammation (Camhi et al., 1995; Ji et al., 2004). Therefore, acute brain inflammation may not last for months in the absence of a fresh trigger.

Intriguingly, microglia studied in vivo expressed very low levels (if any) of neurotoxic inflammatory mediators including iNOS (Ji et al., 2007; Matsumoto et al., 2007), although microglia in pure culture synthesized high amounts of iNOS and TNF- $\alpha$ (Chao et al., 1992; Meda et al., 1995). This difference in inflammatory response in vitro and in vivo may reflect an influence of astrocytes, which inhibit microglial activities (Vincent et al., 1997; Pyo et al., 2003; Min et al., 2006). Dehydroepiandrosterone (DHEA) and prostaglandins are candidate anti-inflammatory factors secreted by astrocytes (Zwain and Yen, 1999; Molina-Holgado et al., 2000; Taniura et al., 2002). DHEA inhibits the activation of nuclear factor-kappaB (NF-kB) induced by TNF- $\alpha$ (Altman et al., 2008) whereas prostaglandin E2 decreases Akt activation and the nuclear translocation of NF-kB (Shi et al., 2010). Astrocytes remained healthy in the brains of animals injected iv with LPS (Figure 1B), and possibly secreted anti-inflammatory factors suppressing microglial expression of inflammatory mediators. In addition, activated microglia produce neurotrophic factors such as transforming growth factor- $\beta 1$, neurotrophin- 3 , and brain-derived neurotrophic factor (Elkabes et al., 1996; Lehrmann et al., 1998; Batchelor et al., 1999; Streit, 2002; Streit, 2005). Furthermore, not all inflammatory mediators produced in the brain are neurotoxic. For example, the effect of IL-1 $\beta$ on neuronal viability is controversial; the material has been suggested to be neurotoxic (Patel et al., 2003; Viviani et al., 2003; Thornton et al., 2006) or neurotrophic/neuroprotective (Strijbos and Rothwell, 1995).

Although systemic inflammation alone does not induce dopaminergic neuronal injury in the SNpc, we cannot exclude the possibility that systemic inflammation may yet be a risk factor for development of neurodegenerative disease. Systemic inflammation may convert a subtoxic insult to toxicity, and/or mild toxicity to potent toxicity. Although parkin-deficient mice do not display degeneration of dopaminergic neurons in the SNpc (Goldberg et al., 2003; Itier et al., 2003; Von Coelln et al., 2004; 
Zhu et al., 2007), long-term systemic treatment with low-dose LPS triggered persistent neuroinflammation and selective loss of dopaminergic neurons (Frank-Cannon et al., 2008). In a murine prion disease model, systemic LPS administration aggravated the extent of neuronal death (Cunningham et al., 2005). In support of this possibility, it has been reported that long-term use of NSAIDs (that penetrate lipid membranes only poorly) reduces the risk of neurodegenerative disease development (Chen et al., 2003; Esposito et al., 2007).

In summary, systemic inflammation alone may not be sufficiently toxic to induce neuronal death, even in the SN. However, we cannot exclude the possibility that such inflammation may interact with other insults to enhance neuronal damage Therefore, inhibition of systemic inflammation may reduce the likelihood of brain inflammation, thus helping to protect against neuronal damage and development of neurodegenerative disease.

\section{Methods}

\section{Systemic administration of LPS}

All experiments were performed in accordance with approved animal protocols and guidelines established by the Ajou University School of Medicine Ethics Review Committee for animal experiments. Male Sprague-Dawley (SD) rats $(230-250 \mathrm{~g}$ in weight, 7 weeks of age) were anesthetized by intraperitoneal injection of ketamine (40-80 $\mathrm{mg} / \mathrm{kg})$ and xylazine $(5-10 \mathrm{mg} / \mathrm{kg})$. LPS $(100-500 \mu \mathrm{g}$ in 250 $\mu \mathrm{l}$ aliquots of sterile PBS; Sigma, St. Louis, MO) was administered iv through the tail vein. PBS-injected animals were used as controls.

\section{Tissue preparation}

Rats were anesthetized and transcardially perfused with saline solution containing $0.5 \%(\mathrm{w} / \mathrm{v})$ sodium nitrate and heparin $(10 \mathrm{U} / \mathrm{ml})$, followed by $4 \%(\mathrm{v} / \mathrm{v})$ paraformaldehyde in $0.1 \mathrm{M}$ phosphate buffer, $\mathrm{pH} 7.2$, to achieve tissue fixation. Brains were obtained and post-fixed overnight at $4^{\circ} \mathrm{C}$ in $4 \%(\mathrm{v} / \mathrm{v})$ paraformaldehyde. Fixed brains were added, at $4^{\circ} \mathrm{C}$, to $30 \%(\mathrm{w} / \mathrm{v})$ sucrose solution until the brain segments sank. Six separate series of coronal brain slices, with each slice being $30 \mu \mathrm{m}$ in thickness, were obtained using a sliding microtome (Microm, Walldorf, Germany). For RNA preparation, rats were anesthetized and transcardially perfused with saline solution without paraformaldehyde. Brains were sliced using a Rat Brain Slicer Matrix $(1.0 \mathrm{~mm}$ slice intervals; RBM-4000C; ASI Instruments, Warren, $\mathrm{MI}$ ) and a razor blade. The slice including the needle injection spot was selected, and tissue blocks $(2 \times$ $2 \times 2 \mathrm{~mm}^{3}$ ) just below the needle tip were prepared and stored at $-70^{\circ} \mathrm{C}$ until use.

\section{Immunohistochemistry}

Prior to 3, 3'-diaminobenzidine (DAB) staining, serial sections were rinsed three times with PBS, treated with $3 \%$ (v/v) $\mathrm{H}_{2} \mathrm{O}_{2}$ for $5 \mathrm{~min}$, and rinsed with PBS containing $0.2 \%$ $(\mathrm{v} / \mathrm{v})$ Triton X-100 (PBST). Non-specific binding was blocked by addition of $1 \%(\mathrm{w} / \mathrm{v}) \mathrm{BSA}$ in PBST. Sections were incubated for $2 \mathrm{~h}$ at room temperature with primary antibodies directed against Iba-1 (1:1,000; Wako Pure Chemical Industries, Osaka, Japan), GFAP (1:300; Sigma, St. Louis, MO), MPO (1:1,000; Dako, Glostrup, Denmark), IL-1 $\beta$ (1:200; R\&D Systems, Minneapolis, MN), iNOS (1:200; Abcam, Cambridge, UK), CD68 (1:200; AbD Serotec, Oxford, UK), or tyrosine hydroxylase (TH; 1:2,000; Pelfreeze Biologicals, Rogers, AR). Following rinsing with PBST, sections were incubated with biotinylated secondary antibodies (Vector Laboratories, Burlingame, CA) and the avidin/biotin system (Vector Laboratories), and bands were visualized using $0.05 \%(\mathrm{w} / \mathrm{v})$ DAB and $0.003 \%(\mathrm{v} / \mathrm{v})$ hydrogen peroxide in $0.1 \mathrm{M}$ PB. Next, sections were mounted on gelatin-coated slides and examined under a bright-field microscope (Olympus Optical BX51, Tokyo, Japan). Bright-field images were stored using PictureFrame Application 2.3 software. For immunofluorescence staining, sections were washed twice in PBS, treated with $1 \%(w / v) B S A$, and incubated with combinations of antibodies against Iba-1, MPO, iNOS, interleukin-1 $\beta$, and CD68. Visualization was achieved using Alexa Fluor488or Alexa Fluor555-conjugated secondary antibodies (1:600 dilution; Invitrogen, Eugene, OR). DAPI (Vector Laboratories) was employed to detect nuclei. Sections were analyzed by confocal microscopy (Carl Zeiss, Jena, Germany) using $40 \times$ water and $63 \times$ oil immersion objectives at $20^{\circ} \mathrm{C}$, and images were captured using Zeiss LSM510 confocal software (Carl Zeiss, Jena, Germany).

\section{Real-time quantitative polymerase chain reaction (Q-PCR)}

Total RNA was isolated using an Easy-BLUE RNA Extraction Kit (iNtRON, Sungnam, Korea), and cDNA was prepared using Reverse Transcription Master Premix (ELPisbio, Taejeon, Korea), according to the manufacturers' instructions. For Q-PCR, approximately $50 \mathrm{ng}$ cDNA was analyzed using a KAPA SYBR FAST qPCR Kit (KAPA Biosystems, Boston, MA) and a Corbett Rotor-Gene 6000 real-time rotary analyzer (Corbett Research, Mortlake, NSW, Australia). Specific primers amplifying mRNAs encoding IL-1 $\beta$, TNF- $\alpha$, IL-6, and glyceraldehyde-3-phosphate dehydrogenase (GAPDH), and used in Q-PCR, are shown in Supplemental Data Table S1. Q-PCR conditions were as follows: $95^{\circ} \mathrm{C}$ for $30 \mathrm{~s}$; followed by 40 cycles of $95^{\circ} \mathrm{C}$ for $3 \mathrm{~s} \mathrm{(melting),} 55^{\circ} \mathrm{C}$ for $20 \mathrm{~s}$ (annealing), and $72^{\circ} \mathrm{C}$ for $3 \mathrm{~s}$ (elongation). For TNF- $\alpha$, the annealing conditions were modified to include a $63-59^{\circ} \mathrm{C}$ touch-down protocol thus decreasing the temperature by $0.5^{\circ} \mathrm{C}$ per cycle over the first eight cycles. To confirm that single products were amplified under the conditions used, a melting curve analysis was performed for each primer pair, using a melt ramp of $72-95^{\circ} \mathrm{C}$ and raising the temperature by $1^{\circ} \mathrm{C}$ at each step ( $5 \mathrm{~s} / \mathrm{step})$. Amplified products were also viewed after electrophoresis on $1.5 \%(\mathrm{w} / \mathrm{v})$ agarose gels, using ethidium bromide staining. The results were normalized to 


\section{GAPDH levels.}

\section{Stereological analysis of dopaminergic neurons}

The number of $\mathrm{TH}^{+}$neurons in every sixth section of the entire SNpc was counted under a bright-field microscope (Olympus Optical BX51, Tokyo, Japan), using Stereo Investigator software (MBF Bioscience, Williston, VT). Counting frames $(100 \times 100 \mu \mathrm{m})$ were randomly placed over SNpc sections, and $\mathrm{TH}^{+}$neurons were counted using a $40 \times$ objective.

\section{Statistical analysis}

Statistical data are expressed as means \pm SEMs. The significance of between-group differences was analyzed using the one-way ANOVA tool in the Statistical Package for Social Sciences, version 12 (SPSS, Chicago, IL).

\section{Supplemental data}

Supplemental Data include a figure and a table and can be found with this article online at http://e-emm.or.kr/article/ article_files/SP-42-12-4.pdf.

\section{Acknowledgements}

This work was supported by a KOSEF NRL Program grant funded by the Korean government (MEST) (no. 22008025-0), a grant (no. M103KV010011-06K2201-01110) from the Brain Research Center of the 21st Century Frontier Research Program of the Ministry of Science and Technology, Republic of Korea, and a grant (no. R132003-019) from KOSEF through the Chronic Inflammatory Disease Research Center (CIDRC) at Ajou University; all to E. Joe.

\section{References}

Aktan F. iNOS-mediated nitric oxide production and its regulation. Life Sci 2004;75:639-53

Altman R, Motton DD, Kota RS, Rutledge JC. Inhibition of vascular inflammation by dehydroepiandrosterone sulfate in human aortic endothelial cells: roles of PPARalpha and NF-kappaB. Vascul Pharmacol 2008;48:76-84

Batchelor PE, Liberatore GT, Wong JY, Porritt MJ, Frerichs F, Donnan GA, Howells DW. Activated macrophages and microglia induce dopaminergic sprouting in the injured striatum and express brain-derived neurotrophic factor and glial cell line-derived neurotrophic factor. J Neurosci 1999;19:1708-16

Blum-Degen D, Muller T, Kuhn W, Gerlach M, Przuntek H, Riederer P. Interleukin-1 beta and interleukin- 6 are elevated in the cerebrospinal fluid of Alzheimer's and de novo Parkinson's disease patients. Neurosci Lett 1995;202:17-20

Bogdan C. Nitric oxide and the immune response. Nat Immunol 2001;2:907-16
Bohatschek M, Werner A, Raivich G. Systemic LPS injection leads to granulocyte influx into normal and injured brain: effects of ICAM-1 deficiency. Exp Neurol 2001;172:137-52

Breitner JC. The role of anti-inflammatory drugs in the prevention and treatment of Alzheimer's disease. Annu Rev Med 1996;47:401-11

Camhi SL, Alam J, Otterbein L, Sylvester SL, Choi AM. Induction of heme oxygenase-1 gene expression by lipopolysaccharide is mediated by AP-1 activation. Am J Respir Cell Mol Biol 1995;13:387-98

Cao C, Matsumura K, Ozaki M, Watanabe Y. Lipopolysaccharide injected into the cerebral ventricle evokes fever through induction of cyclooxygenase-2 in brain endothelial cells. J Neurosci 1999;19:716-25

Chao CC, Hu S, Molitor TW, Shaskan EG, Peterson PK. Activated microglia mediate neuronal cell injury via a nitric oxide mechanism. J Immunol 1992;149:2736-41

Chen $\mathrm{H}$, Zhang SM, Hernan MA, Schwarzschild MA, Willett WC, Colditz GA, Speizer FE, Ascherio A. Nonsteroidal anti-inflammatory drugs and the risk of Parkinson disease. Arch Neurol 2003;60:1059-64

Chen $\mathrm{H}$, Jacobs E, Schwarzschild MA, McCullough ML, Calle EE, Thun MJ, Ascherio A. Nonsteroidal antiinflammatory drug use and the risk for Parkinson's disease. Ann Neurol 2005a;58:963-7

Chen L, Cagniard B, Mathews T, Jones S, Koh HC, Ding Y, Carvey PM, Ling Z, Kang UJ, Zhuang X. Age-dependent motor deficits and dopaminergic dysfunction in DJ-1 null mice. J Biol Chem 2005b;280:21418-26

Chow CC, Clermont G, Kumar R, Lagoa C, Tawadrous Z, Gallo D, Betten B, Bartels J, Constantine G, Fink MP, Billiar $\mathrm{TR}$, Vodovotz $\mathrm{Y}$. The acute inflammatory response in diverse shock states. Shock 2005;24:74-84

Cicchetti F, Brownell AL, Williams K, Chen YI, Livni E, Isacson $O$. Neuroinflammation of the nigrostriatal pathway during progressive 6-OHDA dopamine degeneration in rats monitored by immunohistochemistry and PET imaging. Eur J Neurosci 2002;15:991-8

Croisier E, Moran LB, Dexter DT, Pearce RK, Graeber MB. Microglial inflammation in the parkinsonian substantia nigra: relationship to alpha-synuclein deposition. J Neuroinflammation 2005;2:14

Cunningham C, Wilcockson DC, Campion S, Lunnon K, Perry VH. Central and systemic endotoxin challenges exacerbate the local inflammatory response and increase neuronal death during chronic neurodegeneration. J Neurosci 2005;25:9275-84

da Silva RP, Gordon S. Phagocytosis stimulates alternative glycosylation of macrosialin (mouse CD68), a macrophagespecific endosomal protein. Biochem J 1999;338:687-94

Davalos D, Grutzendler J, Yang G, Kim JV, Zuo Y, Jung S, Littman DR, Dustin ML, Gan WB. ATP mediates rapid microglial response to local brain injury in vivo. Nat Neurosci 2005;8:752-8

Dehmer T, Lindenau J, Haid S, Dichgans J, Schulz JB. Deficiency of inducible nitric oxide synthase protects against 


\section{MPTP toxicity in vivo. J Neurochem 2000;74:2213-6}

Elkabes S, DiCicco-Bloom EM, Black IB. Brain microglia/ macrophages express neurotrophins that selectively regulate microglial proliferation and function. J Neurosci 1996;16:2508-21

Esposito E, Di Matteo V, Benigno A, Pierucci M, Crescimanno G, Di Giovanni G. Non-steroidal anti-inflammatory drugs in Parkinson's disease. Exp Neurol 2007;205: 295-312

Etminan M, Carleton BC, Samii A. Non-steroidal antiinflammatory drug use and the risk of Parkinson disease: a retrospective cohort study. J Clin Neurosci 2008;15:576-7

Frank-Cannon TC, Tran T, Ruhn KA, Martinez TN, Hong J, Marvin M, Hartley M, Trevino I, O'Brien DE, Casey B, Goldberg MS, Tansey MG. Parkin deficiency increases vulnerability to inflammation-related nigral degeneration. J Neurosci 2008;28:10825-34

Gao HM, Jiang J, Wilson B, Zhang W, Hong JS, Liu B. Microglial activation-mediated delayed and progressive degeneration of rat nigral dopaminergic neurons: relevance to Parkinson's disease. J Neurochem 2002;81:1285-97

Gelb DJ, Oliver E, Gilman S. Diagnostic criteria for Parkinson disease. Arch Neurol 1999;56:33-9

Goldberg MS, Fleming SM, Palacino JJ, Cepeda C, Lam HA, Bhatnagar A, Meloni EG, Wu N, Ackerson LC, Klapstein GJ, Gajendiran M, Roth BL, Chesselet MF, Maidment NT, Levine MS, Shen J. Parkin-deficient mice exhibit nigrostriatal deficits but not loss of dopaminergic neurons. J Biol Chem 2003;278:43628-35

Hanisch UK, Kettenmann H. Microglia: active sensor and versatile effector cells in the normal and pathologic brain. Nat Neurosci 2007;10:1387-94

Herrera AJ, Castano A, Venero JL, Cano J, Machado A. The single intranigral injection of LPS as a new model for studying the selective effects of inflammatory reactions on dopaminergic system. Neurobiol Dis 2000;7:429-47

in 't Veld BA, Launer LJ, Breteler MM, Hofman A, Stricker BH. Pharmacologic agents associated with a preventive effect on Alzheimer's disease: a review of the epidemiologic evidence. Epidemiol Rev 2002;24:248-68

Inoue W, Matsumura K, Yamagata K, Takemiya T, Shiraki T, Kobayashi S. Brain-specific endothelial induction of prostaglandin $E(2)$ synthesis enzymes and its temporal relation to fever. Neurosci Res 2002;44:51-61

Itier JM, Ibanez P, Mena MA, Abbas N, Cohen-Salmon C, Bohme GA, Laville M, Pratt J, Corti O, Pradier L, Ret G, Joubert C, Periquet M, Araujo F, Negroni J, Casarejos MJ, Canals S, Solano R, Serrano A, Gallego E, Sanchez M, Denefle P, Benavides J, Tremp G, Rooney TA, Brice A, Garcia de Yebenes J. Parkin gene inactivation alters behaviour and dopamine neurotransmission in the mouse. Hum Mol Genet 2003;12:2277-91

Ji KA, Yang MS, Jou I, Shong MH, Joe EH. Thrombin induces expression of cytokine-induced $\mathrm{SH} 2$ protein $(\mathrm{CIS})$ in rat brain astrocytes: involvement of phospholipase A2, cyclooxygenase, and lipoxygenase. Glia 2004;48:102-11
Ji KA, Yang MS, Jeong HK, Min KJ, Kang SH, Jou I, Joe EH. Resident microglia die and infiltrated neutrophils and monocytes become major inflammatory cells in lipopolysaccharide-injected brain. Glia 2007;55:1577-88

Ji KA, Eu MY, Kang SH, Gwag BJ, Jou I, Joe EH. Differential neutrophil infiltration contributes to regional differences in brain inflammation in the substantia nigra pars compacta and cortex. Glia 2008;56:1039-47

Johanson CE, Duncan JA 3rd, Klinge PM, Brinker T, Stopa EG, Silverberg GD. Multiplicity of cerebrospinal fluid functions: New challenges in health and disease. Cerebrospinal Fluid Res 2008;5:10

Klegeris A, McGeer PL. Non-steroidal anti-inflammatory drugs (NSAIDs) and other anti-inflammatory agents in the treatment of neurodegenerative disease. Curr Alzheimer Res 2005;2:355-65

Klein C, Djarmati A, Hedrich K, Schafer N, Scaglione C, Marchese R, Kock N, Schule B, Hiller A, Lohnau T, Winkler S, Wiegers K, Hering R, Bauer P, Riess O, Abbruzzese G, Martinelli P, Pramstaller PP. PINK1, Parkin, and DJ-1 mutations in Italian patients with early-onset parkinsonism. Eur J Hum Genet 2005;13:1086-93

Klein C, Schlossmacher MG. The genetics of Parkinson disease: Implications for neurological care. Nat Clin Pract Neurol 2006;2:136-46

Knott C, Stern G, Wilkin GP. Inflammatory regulators in Parkinson's disease: iNOS, lipocortin-1, and cyclooxygenases-1 and -2. Mol Cell Neurosci 2000;16:724-39

Kreutzberg GW. Microglia: a sensor for pathological events in the CNS. Trends Neurosci 1996;19:312-8

Lehrmann E, Kiefer R, Christensen T, Toyka KV, Zimmer J, Diemer NH, Hartung HP, Finsen B. Microglia and macrophages are major sources of locally produced transforming growth factor-beta1 after transient middle cerebral artery occlusion in rats. Glia 1998;24:437-48

Liaudet L, Murthy KG, Mabley JG, Pacher P, Soriano FG, Salzman AL, Szabo C. Comparison of inflammation, organ damage, and oxidant stress induced by Salmonella enterica serovar Muenchen flagellin and serovar Enteritidis lipopolysaccharide. Infect Immun 2002;70:192-8

Liberatore GT, Jackson-Lewis V, Vukosavic S, Mandir AS Vila M, McAuliffe WG, Dawson VL, Dawson TM, Przedborski $\mathrm{S}$. Inducible nitric oxide synthase stimulates dopaminergic neurodegeneration in the MPTP model of Parkinson disease. Nat Med 1999;5:1403-9

Liu B, Du L, Hong JS. Naloxone protects rat dopaminergic neurons against inflammatory damage through inhibition of microglia activation and superoxide generation. J Pharmacol Exp Ther 2000;293:607-17

Matsumoto H, Kumon Y, Watanabe H, Ohnishi T, Shudou M, li C, Takahashi H, Imai Y, Tanaka J. Antibodies to CD11b, CD68, and lectin label neutrophils rather than microglia in traumatic and ischemic brain lesions. J Neurosci Res 2007;85:994-1009

McGeer PL, Itagaki S, Boyes BE, McGeer EG. Reactive microglia are positive for HLA-DR in the substantia nigra of 
Parkinson's and Alzheimer's disease brains. Neurology 1988;38:1285-91

Meda L, Cassatella MA, Szendrei GI, Otvos L Jr, Baron P, Villalba M, Ferrari D, Rossi F. Activation of microglial cells by beta-amyloid protein and interferon-gamma. Nature 1995; 374:647-50

Min KJ, Yang MS, Jou I, Joe EH. Protein kinase A mediates microglial activation induced by plasminogen and gangliosides. Exp Mol Med 2004;36:461-7

Min KJ, Yang MS, Kim SU, Jou I, Joe EH. Astrocytes induce hemeoxygenase-1 expression in microglia: a feasible mechanism for preventing excessive brain inflammation. $J$ Neurosci 2006;26:1880-7

Mogi M, Harada M, Kondo T, Riederer P, Inagaki H, Minami M, Nagatsu T. Interleukin-1 beta, interleukin-6, epidermal growth factor and transforming growth factor-alpha are elevated in the brain from parkinsonian patients. Neurosci Lett 1994;180:147-50

Molina-Holgado E, Ortiz S, Molina-Holgado F, Guaza C. Induction of COX-2 and PGE(2) biosynthesis by IL-1 beta is mediated by PKC and mitogen-activated protein kinases in murine astrocytes. Br J Pharmacol 2000;131:152-9

Muller T, Blum-Degen D, Przuntek H, Kuhn W. Interleukin-6 levels in cerebrospinal fluid inversely correlate to severity of Parkinson's disease. Acta Neurol Scand 1998:98:142-4

Nagatsu T, Sawada M. Inflammatory process in Parkinson's disease: role for cytokines. Curr Pharm Des 2005;11:9991016

Nerlich AG, Weiler C, Zipperer J, Narozny M, Boos N. Immunolocalization of phagocytic cells in normal and degenerated intervertebral discs. Spine (Phila Pa 1976) 2002;27:2484-90

Patel HC, Boutin H, Allan SM. Interleukin-1 in the brain: mechanisms of action in acute neurodegeneration. Ann NY Acad Sci 2003;992:39-47

Perry VH, Cunningham C, Holmes C. Systemic infections and inflammation affect chronic neurodegeneration. Nat Rev Immunol 2007;7:161-7

Possel H, Noack H, Putzke J, Wolf G, Sies H. Selective upregulation of inducible nitric oxide synthase (iNOS) by lipopolysaccharide (LPS) and cytokines in microglia: in vitro and in vivo studies. Glia 2000;32:51-9

Pyo $\mathrm{H}$, Yang MS, Jou I, Joe EH. Wortmannin enhances lipopolysaccharide-induced inducible nitric oxide synthase expression in microglia in the presence of astrocytes in rats Neurosci Lett 2003;346:141-4

Qin L, Wu X, Block ML, Liu Y, Breese GR, Hong JS, Knapp DJ, Crews FT. Systemic LPS causes chronic neuroinflammation and progressive neurodegeneration. Glia 2007;55 453-62

Raivich G, Bohatschek M, Kloss CU, Werner A, Jones LL, Kreutzberg GW. Neuroglial activation repertoire in the injured brain: graded response, molecular mechanisms and cues to physiological function. Brain Res Brain Res Rev 1999;30:77-105
Rezaie P, Corbisiero V, Male D. Transient expression of MIDC-8 in the normal mouse brain. Neurosci Lett 2005;377:189-94

Rockenstein E, Mallory M, Hashimoto M, Song D, Shults CW, Lang I, Masliah E. Differential neuropathological alterations in transgenic mice expressing alpha-synuclein from the platelet-derived growth factor and Thy-1 promoters. J Neurosci Res 2002;68:568-78

Rummel C, Inoue W, Sachot C, Poole S, Hubschle T, Luheshi GN. Selective contribution of interleukin- 6 and leptin to brain inflammatory signals induced by systemic LPS injection in mice. J Comp Neurol 2008;511:373-95

Samii A, Etminan M, Wiens MO, Jafari S. NSAID use and the risk of Parkinson's disease: systematic review and metaanalysis of observational studies. Drugs Aging 2009;26:76979

Saper CB. The dance of the perivascular and endothelial cells: mechanisms of brain response to immune signaling. Neuron 2010;65:4-6

Shi J, Johansson J, Woodling NS, Wang Q, Montine TJ, Andreasson K. The prostaglandin E2 E-prostanoid 4 receptor exerts anti-inflammatory effects in brain innate immunity. J Immunol 2010;184:7207-18

Sriram K, Matheson JM, Benkovic SA, Miller DB, Luster MI, O'Callaghan JP. Deficiency of TNF receptors suppresses microglial activation and alters the susceptibility of brain regions to MPTP-induced neurotoxicity: role of TNF-alpha. FASEB J 2006;20:670-82

Streit WJ. Microglia as neuroprotective, immunocompetent cells of the CNS. Glia 2002;40:133-9

Streit WJ. Microglia and neuroprotection: implications for Alzheimer's disease. Brain Res Brain Res Rev 2005;48: 234-9

Strijbos PJ, Rothwell NJ. Interleukin-1 beta attenuates excitatory amino acid-induced neurodegeneration in vitro: involvement of nerve growth factor. J Neurosci 1995;15: 3468-74

Taniura S, Kamitani H, Watanabe T, Eling TE. Transcriptional regulation of cyclooxygenase- 1 by histone deacetylase inhibitors in normal human astrocyte cells. J Biol Chem 2002;277:16823-30

Thomas B, Beal MF. Parkinson's disease. Hum Mol Genet 2007; 16:R183-94

Thornton P, Pinteaux E, Gibson RM, Allan SM, Rothwell NJ. Interleukin-1-induced neurotoxicity is mediated by glia and requires caspase activation and free radical release. $J$ Neurochem 2006;98:258-66

Vijitruth R, Liu M, Choi DY, Nguyen XV, Hunter RL, Bing G. Cyclooxygenase-2 mediates microglial activation and secondary dopaminergic cell death in the mouse MPTP model of Parkinson's disease. J Neuroinflammation 2006; $3: 6$

Vincent VA, Tilders FJ, Van Dam AM. Inhibition of endotoxininduced nitric oxide synthase production in microglial cells by the presence of astroglial cells: a role for transforming growth factor beta. Glia 1997;19:190-8 
Viviani B, Bartesaghi S, Gardoni F, Vezzani A, Behrens MM, Bartfai T, Binaglia M, Corsini E, Di Luca M, Galli CL, Marinovich M. Interleukin-1 beta enhances NMDA receptormediated intracellular calcium increase through activation of the Src family of kinases. J Neurosci 2003;23:8692-700

Von Coelln R, Thomas B, Savitt JM, Lim KL, Sasaki M, Hess EJ, Dawson VL, Dawson TM. Loss of locus coeruleus neurons and reduced startle in parkin null mice. Proc Natl Acad Sci USA 2004;101:10744-9

Whitton PS. Inflammation as a causative factor in the aetiology of Parkinson's disease. Br J Pharmacol 2007;150: 963-76
Wu DC, Jackson-Lewis V, Vila M, Tieu K, Teismann P, Vadseth C, Choi DK, Ischiropoulos H, Przedborski S. Blockade of microglial activation is neuroprotective in the 1-methyl-4-phenyl-1,2,3,6-tetrahydropyridine mouse model of Parkinson disease. J Neurosci 2002;22:1763-71

Zhu XR, Maskri L, Herold C, Bader V, Stichel CC, Gunturkun $\mathrm{O}$, Lubbert $\mathrm{H}$. Non-motor behavioural impairments in parkin-deficient mice. Eur J Neurosci 2007;26:1902-11

Zwain IH, Yen SS. Neurosteroidogenesis in astrocytes, oligodendrocytes, and neurons of cerebral cortex of rat brain. Endocrinology 1999;140:3843-52 